\title{
Fatores predisponentes das complicações incisionaisde laparotomias medianas em eqüinos
}

\author{
Predisposal factors to incisional complications of ventral midline laparotomies in horses
}

\author{
Geane Maciel Pagliosa ${ }^{1}$ Geraldo Eleno Silveira Alves ${ }^{2}$
}

\section{- REVISÃO BIBLIOGRÁFICA -}

\section{RESUMO}

\begin{abstract}
As complicações incisionais após laparotomia mediana em eqüinos têm prevalência de 35 a 87,5\% e levam a aumento no período de convalescença ou mesmo ao óbito. Os fatores predisponentes destas complicações são pouco abordados na literatura médica eqüina e são inerentes ao paciente, ao ato cirúrgico, à anestesia e ao período pósoperatório. Considerações sobre os cuidados no préoperatório, tamanho da incisão, roupa do cirurgião, escolha do fio cirúrgico e as condições clínicas e comportamentais do eqüino são salientadas entre os fatores predisponentes que, quando bem conhecidos, podem ser melhor administrados, no sentido de minimizar as complicações incisionais na laparotomia mediana.
\end{abstract}

Palavras-chave: cirurgia, abdome agudo, cicatrização, fios de sutura, convalescença.

\section{ABSTRACT}

Incisional complications after equine midline laparotomy have an incidence of 35 to $87.5 \%$ and lead an increase in the convalescence period or to death. Predisposed factors to these complications are little approached in the equine medicine literature and consist of inherent factors to the patient, surgery, anesthesia and postoperative period. Preoperative cares, size of the incision, surgeon clothes, the choice of the suture material and equine clinical and behaviour conditions may be considered and well known in order to decrease the incisional complications after the midline laparotomy.

Key words: surgery, colic, healing, convalescence, suture.

\section{INTRODUÇÃO}

A laparotomia mediana é a via de acesso mais utilizada para a abordagem cirúrgica em eqüinos com cólica, permitindo a maior área de inspeção dos órgãos abdominais. Devido à natureza fibrosa e escassez vascular da linha alba, há menor hemorragia durante a incisão e maior resistência às forças de tensão da sutura e peso das vísceras abdominais durante a cicatrização (EDWARDS, 1988; TROSTLE et al., 1994). Por outro lado, a cicatrização é relativamente mais lenta quando comparada àquelas que ocorrem após laparotomias paramediana ou pelo flanco e, como essas, está sujeita a fatores locais, sistêmicos e cirúrgicos que podem trazer complicações variáveis.

Apesar dos avanços no conhecimento científico e do aumento da taxa de sobrevida de eqüinos submetidos a intervenções cirúrgicas abdominais, a prevalência de complicações incisionais nas laparotomias medianas pode chegar a $35 \%$, ou mesmo 87,5\% quando de uma reintervenção (KOBLUK et al., 1989). As complicações incisionais na laparotomia mediana retardam a cicatrização da ferida cirúrgica aumentando o período de convalescença e algumas podem, ser fatais. Devido à importância do conhecimento dos fatores predisponentes às complicações após a laparotomia mediana para o completo sucesso cirúrgico, esta revisão objetiva

${ }^{1}$ Médico Veterinário, estudante do Curso de Pós-graduação em Clínica e Cirurgia Veterinárias, Escola de Veterinária da Universidade Federal de Minas Gerais (UFMG), Belo Horizonte, MG. E-mail: geanepagliosa@bol.com.br Av. Alfredo Camarate, 310, Bairro São Luiz, Pampulha, 31310-000, Belo Horizonte, MG. Autor para correspondência.

${ }^{2}$ Médico Veterinário, Doutor em Ciência Animal, Professor Adjunto, Escola de Veterinária, UFMG. 
abordar esses fatores predisponentes, os quais se encontram dispersos e sucintamente tratados na literatura médica eqüina.

\section{FATORESPREDISPONENTES}

As complicações associadas à laparotomia mediana nos eqüinos (Tabela 1) decorrem de diversos fatores predisponentes, nos quais se incluem os fatores inerentes ao paciente, a cirurgia, a anestesia e ao período pós-operatório.

\section{Fatores inerentes ao paciente}

Idade, raça e peso

Em eqüinos jovens, a cicatrização é mais rápida, com menor susceptibilidade a infecções (STASHAK, 1991). WILSON et al. (1995) encontraram em 436 eqüinos analisados uma prevalência de 4 a $15 \%$ de complicações após laparotomia em eqüinos de até um ano de idade contra $43 \%$ em adultos. Entre as raças, a PSI e a Quarto de Milha possuem maior prevalência de complicações incisionais com um índice de até 52 e 53,8\%, respectivamente (WILSON et al., 1995; HONNAS \& COHEN, 1997). Segundo WILSON et al. (1995), a chance de complicações incisionais em eqüinos com peso acima de $300 \mathrm{~kg}$ é cinco vezes maior.

\section{Estado nutricional}

Em eqüinos com desequilíbrios nutricionais, a cicatrização é retardada e há maior susceptibilidade para infecções pós-cirúrgicas. A hipoproteinemia prolonga a cicatrização alterando a fibroplasia, angiogênese e a remodelação do colágeno, além de colaborar para a imunossupressão (TURNER, 1978). Os aminoácidos cistina e metionina são especialmente importantes na síntese do colágeno. Concentrações séricas de proteínas totais abaixo de $5,5 \mathrm{mg} \mathrm{dl}^{-1}$ afetam em $70 \%$ a cicatrização e de $2 \mathrm{mg} \mathrm{dl}^{-1}$ a inibem completamente (STASHAK, 1991).

Algumas vitaminas e minerais também participam do processo de cicatrização. As vitaminas A e C atuam na epitelização, síntese de colágeno e angiogênese, enquanto a vitamina $\mathrm{E}$ auxilia na estabilização da membrana celular. O cobre participa na formação e maturação do colágeno e o zinco na epitelização, proliferação de fibroblastos, síntese de colágeno e manutenção da resistência tênsil da ferida. No entanto, complicações incisionais devido a deficiências vitamínicas e minerais são incomuns e a suplementação pouco contribui para auxiliar a

Tabela 1 - Origens, características e consequiências das complicações associadas à laparotomia mediana nos eqüinos.

\begin{tabular}{|c|c|c|c|}
\hline Complicações & Origens & Características & Conseqüências \\
\hline Edema & Inflamação, infecção & Aumento de volume & $\begin{array}{l}\text { Cicatrização retardada, } \\
\text { deiscência da sutura }\end{array}$ \\
\hline Drenagem incisional & Inflamação, sutura indevida & $\begin{array}{l}\text { Exsudato seroso ou } \\
\text { serosanguinolento }\end{array}$ & $\begin{array}{l}\text { Cicatrização retardada, infecção, } \\
\text { hérnia }\end{array}$ \\
\hline Hematoma e seroma & Sutura indevida & Aumento de volume & Necrose, deiscência \\
\hline Infecção & Bactérias da pele e microbiota intestinal & Exsudato pela ferida & $\begin{array}{l}\text { Retardo cicatricial, peritonite, } \\
\text { aderência }\end{array}$ \\
\hline Peritonite & $\begin{array}{l}\text { Trauma,infecção, enterotomia/ } \\
\text { enterectomia }\end{array}$ & $\begin{array}{l}\text { Tensão abdominal, debilidade } \\
\text { orgânica }\end{array}$ & Morbidade grave, óbito \\
\hline Aderência & Laparotomia repetida, infecção, inflamaçãc & Obstrução intestinal mecânica & Cólica intermitente, óbito \\
\hline Deiscência & $\begin{array}{l}\text { Sutura indevida, edema,evisceração do } \\
\text { omento, dor abdominal }\end{array}$ & Drenagem, hérnia, eventração & Evisceração, óbito \\
\hline Hérnia & $\begin{array}{l}\text { Sutura indevida,hipoproteinemia, } \\
\text { infecção }\end{array}$ & Aumento de volume, anel herniário & $\begin{array}{l}\text { Encarceramento e } \\
\text { estrangulamento intestinal }\end{array}$ \\
\hline Eventração & Deiscência de sutura & Aumento de volume & Encarceramento \\
\hline Evisceração & Deiscência da ferida, eventração & Exposição de vísceras & Choque, óbito \\
\hline
\end{tabular}

(Adaptado de WHITE II, 1990).

Ciência Rural, v.34, n.5, set-out, 2004. 
cicatrização, a não ser em eqüinos com debilidade intensa (TURNER, 1978; STASHAK, 1991).

Anemia, tensão de oxigênio tissular e leucopenia Os eqüinos anêmicos normovolêmicos devido à desnutrição ou doenças crônicas, podem ter uma cicatrização normal uma vez que a anemia, isoladamente, não altera a tensão de oxigênio tissular (TURNER, 1978). Por outro lado, a isquemia, causada pela tensão presente em áreas de edema ou sutura apertada, altera o metabolismo, aumentando o tempo de cicatrização e o risco de infecção (INGLE-FEHR et al., 1997).

A leucopenia em eqüinos aumenta em 2,3 vezes a chance de ocorrer drenagem pela ferida operatória abdominal (GIBSON et al., 1989), a qual constitui importante fator predisponente à hérnia incisional, uma vez que aumenta em até dezessete vezes sua incidência (HONNAS \& COHEN, 1997; FRENCH et al., 2002).

Dor e estresse

A dor acarreta estresse que aumenta a atividade simpática, gerando desequilíbrios neuroendócrinos como a elevação da concentração sérica de cortisol, o que contribui para o retardo da angiogênese e fibroplasia (TURNER, 1978; BAXTER, 1992).

\section{Fatores inerentes ao ato cirúrgico e à anestesia}

Técnica

A técnica cirúrgica deve ser praticada sob condições adequadas de assepsia, hemostasia e trauma mínimo nas bordas da incisão (KOBLUK et al., 1989; INGLE-FHER et al., 1997). Apesar de mais de $20 \%$ das bactérias cutâneas serem inacessíveis a qualquer desinfecção, a maior fonte de contaminação da incisão cirúrgica é endógena (INGLE-FHER et al., 1997). O tamanho da incisão deve ser adequado, evitando-se excessos, especialmente no sentido cranial, onde a linha alba é mais delgada e menos resistente à tensão da sutura (TROSTLE et al., 1994). Por outro lado, incisões pequenas facilitam a ocorrência de lesões nas bordas da ferida pelo braço do cirurgião e vísceras. Embora não descrito na literatura consultada, a roupa do cirurgião também pode contribuir na ocorrência de lesões não somente nas bordas da ferida como também durante a manipulação das vísceras. Tecidos de algodão espessos acarretam traumas indevidos, sendo mais adequados os capotes cirúrgicos com mangas impermeáveis e lisas. A manutenção da umidade das vísceras expostas minimiza a ocorrência de aderências (ALVES, 1997).
Fios de diversos materiais têm sido utilizados para laparorrafia em eqüinos (Tabela 2). O categute mais utilizado no passado para sutura da linha alba, atualmente é dispensado devido à sua alta reatividade associada à hérnia e deiscência da ferida (KAWCAK \& STASHAK, 1995; WHITE, 1996). A poliamida, por outro lado, é indicada para a sutura da linha alba devido à sua natureza relativamente inerte e pela ação bactericida dos produtos de sua degradação (McILWRAITH, 1978). No entanto, devido à possibilidade de afrouxamento dos nós pelo baixo coeficiente de atrito e pela memória elevada, a poliamida exige sobrenós adicionais (ROSIN \& ROBINSON, 1989; TROSTLE et al., 1994). O polipropileno também é indicado não só pela sua natureza inerte, mas pela alta estabilidade do nó (BLACKFORD \& BLACKFORD, 1992). O poliéster e o ácido poliglicólico são mais resistentes e dão mais estabilidade aos nós da sutura, entretanto, o poliéster facilita a ocorrência de infecção e o ácido poliglicólico apresenta diminuição rápida de sua resistência tênsil (CAMPBELL \& BAILEY, 1992). A poliglactina 910, apesar de ser amplamente empregada na sutura da linha alba, pode facilitar o desenvolvimento de infecção, o que é atribuído à sua apresentação multifilamentosa (HONNAS \& COHEN, 1997). A polidioxanona é mais adequada para a sutura da linha alba, com a vantagem de manter a resistênsia tênsil por mais tempo que a poliglactina e o ácido poliglicólico (BLACKFORD \& BLACKFORD, 1992).

De maneira geral, os fios multifilamentosos são mais resistentes à tensão e permitem nós mais

Tabela 2 - Vantagens e desvantagens dos fios de sutura utilizados na laparorrafia mediana em eqüinos.

\begin{tabular}{|c|c|c|}
\hline Fio & Vantagem & Desvantagem \\
\hline Poliamida $^{\text {b,c/d }}$ & Inerte & Menor segurança do nó \\
\hline Poliéster ${ }^{\mathrm{b}, \mathrm{d}}$ & Alta resistência & Potencial para fístula \\
\hline $\begin{array}{l}\text { Ácido } \\
\text { poliglicólico }^{\mathrm{a}, \mathrm{d}}\end{array}$ & $\begin{array}{l}\text { Efeito actericida } \\
\text { dos produtos da } \\
\text { degradação }\end{array}$ & $\begin{array}{l}\text { Perda de } 80 \% \text { da tensão } \\
\text { em } 14 \text { dias }\end{array}$ \\
\hline Poliglactina $910^{\mathrm{a}, \mathrm{d}}$ & Fácil manuseio & $\begin{array}{l}\text { Perda de } 80 \% \text { da tensão } \\
\text { em } 14 \text { dias }\end{array}$ \\
\hline Polidioxanona $^{\mathrm{a}, \mathrm{c}}$ & $\begin{array}{l}\text { Absorção } \\
\text { completa } \\
\text { em } 182 \text { dias }\end{array}$ & $\begin{array}{l}\text { Perda de } 50 \% \text { da tensão } \\
\text { em } 14 \text { dias }\end{array}$ \\
\hline Polipropileno ${ }^{\mathrm{b}, \mathrm{c}}$ & Inerte & Difícil manuseio \\
\hline
\end{tabular}

${ }^{\mathrm{a}}$ Absorvível, ${ }^{\mathrm{b}}$ Não absorvível, ${ }^{\mathrm{c}}$ Monofilamento, ${ }^{\mathrm{d}}$ Multifilamento. (Adaptado de DUCHARME et al., 1992) 
estáveis que os monofilamentosos, entretanto podem facilitar a capilaridade, o que representa um fator adicional à infecção, e podem promover o corte no tecido por ocasião da sutura ou edema pós-cirúrgico devido ao efeito serra (CAMPBELL \& BAILEY, 1992).

Entre os padrões de sutura empregados na laparorrafia da linha alba, o mais utilizado é o de pontos simples separados, embora a sutura contínua não acarrete riscos maiores (TURNER \& YOVICH, 1988). No entanto, em humanos com distensão abdominal, o padrão contínuo apresenta vantagem em relação ao isolado que, nessa condição, sofre um aumento no intervalo entre os pontos, possibilitando risco maior de hérnia incisional (SCARAVANCI \& TARNOVSCHI, 1993).

A entrada da agulha para laparorrafia mediana deve obedecer a um afastamento de dez a quinze milímetros da borda da incisão, o que garante uma distância segura da área de colagenólise (TURNER, 1988; TROSTLE et al., 1994; INGLE-FHER, 1997). O músculo reto abdominal não deve ser incluído na sutura para evitar o risco de necrose (McILWRAITH, 1978).

$\mathrm{Na}$ escolha do fio para sutura, deve-se considerar não somente seu grau de reatividade ou segurança dos nós, mas o tipo e o estado geral do paciente. Se o eqüino é obeso, é preferível o uso de padrões de sutura do tipo Mattres, que proporcionam maior resistência Em eqüinos submetidos a uma segunda ou terceira intervenção, deve-se considerar que a cicatrização da linha alba é mais demorada e, portanto, é necessário fios mais resistentes, com tempo de absorção mais prolongado, como a polidioxanona ou poliamida. Em eqüinos leucopênicos e com comprometimento intestinal considerável, o fio deve ser o mais inerte devido aos riscos maiores de inflamação e infecção. Fios agulhados em agulhas atraumáticas, apesar de maior dificuldade de penetração na linha alba, são preferíveis para a laparorrafia mediana pela menor possibilidade de ruptura dos tecidos quando do ajuste da sutura e deiscência da ferida, que poderá ocorrer também se a sutura for incorretamente apertada, gerando isquemia.

\section{Tipo e tempo cirúgicos}

As intervenções cirúrgicas em eqüinos para o tratamento de cólica através de laparotomia mediana resultam numa maior freqüência de complicações incisionais, especialmente em casos de obstrução intestinal que requerem enterotomia e/ou enterectomia (KOBLUK et al., 1989; PHILLIPS \& WALMSLEY, 1993; WILSON et al., 1995; INGLE-FHER et al., 1997), os quais aumentam a incidência de hérnia incisional em até $16 \%$ (WHITE, 1996).
As laparotomias repetidas resultam em maior possibilidade de complicações incisionais, entre elas as aderências (BAXTER, 1992; WHITE, 1996; HONNAS \& COHEN, 1997; MORTON \& BLIKSLAGER, 2002). Os procedimentos cirúrgicos com mais de duas horas de duração acarretam duas vezes mais chance de complicações incisionais (PHILLIPS \& WALMSLEY, 1993; WILSON et al., 1995).

\section{Recuperação anestésica}

Um protocolo anestésico correto com manutenção da pressão arterial acima de $60 \mathrm{mmHg}$, fluidoterapia suficiente e mesa cirúrgica com colchão adequado, minimizam transtornos de excitação do eqüino durante a recuperação anestésica que resultam em neuromiopatias, traumatismos e pressões bruscas na sutura com risco de deiscência (McILWRAITH, 1978).

As complicações anestésicas e o tempo cirúrgico podem ser minimizados com a capacitação adequada da equipe cirúrgica que deve aliar habilidade e eficiência no domínio da técnica e conhecer as individualidades da espécie.

\section{Fatores inerentes ao período pós-operatório}

A bandagem abdominal, apesar de promover suporte e proteção da ferida cirúgica e prevenir o edema nas regiões adjacentes à incisão, pode ocasionar dispnéia quando muito apertada e acúmulo de exsudato na ferida cirúrgica abdominal, devendo também ser evitada em dias muito quentes e úmidos (WHITE II, 1990; DUCHARME et al., 1992). Um ajuste adequado da bandagem abdominal, sem pressões excessivas que possam abafar excessivamente a ferida ou trazer incômodo ao eqüino seria o ideal. O retorno ao exercício deve ser gradativo, variando de seis semanas a três meses, dependendo do tamanho da incisão, mas o exercício a passo controlado é fundamental durante o primeiro mês após a intervenção (WHITE II, 1990). A movimentação do eqüino durante o pós-operatório imediato contribui para minimizar o edema e o estresse.

\section{CONCLUSÕES}

Toda intervenção cirúrgica abdominal acarreta risco de complicações incisionais, pois são vários os fatores predisponentes possíveis. Durante os períodos pré, trans e pós cirúrigicos é imperativo que todos esses fatores sejam identificados, avaliados e minimizados ou abolidos, na medida do possível. 


\section{REFERÊNCIAS BIBLIOGRÁFICAS}

ALVES, G.E.S. Tratamento da peritonite experimental em eqüinos com a associação de dimetilsulfóxido, heparina e enrofloxacina: estudo clínico, cirúrgico e da patologia. 1997. 180f. Tese (Doutorado em Ciência Animal) - Curso de Pós-graduação em Medicina Veterinária, Universidade Federal de Minas Gerais.

BAXTER, C.M. Recognizing and managing the postoperative complications of equine abdominal surgery. Equine Pract, v.87, n.11, p.1113-1120, 1992.

BLACKFORD, L.A.W.; BLACKFORD, J.T. Wound closure In: AUER, J.A. Equine surgery. Philadelphia : Saunders, 1992. Cap.16. p.135-151.

.CAMPBELL, E.J.; BAILEY, J.V. Mechanical properties of suture materials in vitro and after in vivo implantation in horses. Vet Surg, v.21, n.5, p.355-361, 1992.

DUCHARME, N.G. et al. Principles of intestinal surgery. In: AUER, J.A. Equine surgery. Philadelphia: Saunders, 1992. Cap.33, p.325-348.

EDWARDS, G.B. Cirurgia abdominal. In: HICKMAN, J. Cirugia y medicina equinas. Buenos Aires : Hemisferio Sur, 1988. Cap.2, p.123-216.

.FRENCH, N.P. et al. Equine surgical colic: risk factors for postoperative complications. Equine Vet J, v.24, n.5, p.444449, 2002.

GIBSON, K.T. et al. Incisional hernias in the horse: incidence and predisposing factors. Vet Surg, v.18, n.5, p.360-366, 1989.

HONNAS, C.M.; COHEN, N.D. Risk factors for wound infection following celiotomy in horses. J Am Vet Med Ass, v.210, n.1, p.78-81, 1997.

INGLE-FEHR, J.E. et al. Bacterial culturing of ventral median celiotomies for prediction of incisional complications in horses. Vet Surg, v.26, n.1, p.7-13, 1997.

KAWCAK, C.E.; STASHAK, T.S. Predisposing factors, diagnosis, and management of large abdominal wall defects in horses and cattle. J Am Vet Med Ass, v.206, n.5, p.607$611,1995$.

KOBLUK, C.N. et al. Factors affecting incisional complication rates associated with colic surgery in horses: 78 cases (19831985). J Am Vet Med Ass, v.195, n.5, p.639-642, 1989.
McILWRAITH, C.W. Complications of laparotomy incisions in the horse. Proc Am Equine Pract, v.24, p.209218,1978 .

MORTON, A.J.; BLIKSLAGER, A.T. Surgical and postoperative factors influencing short-term survival of horses following small intestinal resection: 92 cases (1994-2001). Equine Vet J, v.34, n.5, p.450-454, 2002 .

PHILLIPS, T.J.; WALMSLEY, J.P. Retrospective analysis of the results of 151 exploratory laparotomies in horses with gastrointestinal disease. Equine Vet J, v.25, n.5, p.427-431, 1993.

ROSIN, E.; ROBINSON, G.M. Knot security of suture materials. Vet Surg, v.18, n.4, p.269-273, 1989.

SCARAVANCI, A.A.; TARNOUSCHI, S. Cirurgia da parede abdominal. In: HERING, F L.O; GABOR, S.; ROSENBERG, D. Bases técnicas e teóricas de fios e suturas. São Paulo : Roca, 1993. Cap.18, p.143-148.

STASHAK, T.S. Selected factors that affect wound healing. In: ____. Equine wound managment. Philadelphia: Lea \& Febiger, 1991. Cap.2, p.19-34.

TROSTLE, S.S. et al. A study of the biomechanical properties of the adult equine linea alba: relationship of tissue bite size and suture material to breaking strength. Vet Surg, v.23, n.6, p.435-441, 1994.

TURNER, A.S.; YOVICH, J.V. Continuous absorbable suture pattern in the closure of ventral midline incisions in horses. Equine Vet J, v.20, n.6, p.401405,1988 .

TURNER, A.S. Local and systemic factors affecting wound healing. Proc Am Equine Pract, v.24, p.355362,1978 .

WHITE, N.A. Incisional hernia after abdominal surgery in the horse. Equine Vet Educ, v.8, n.6, p.308-312, 1996.

WHITE II, N.A. Intensive care, monitoring, and complications of acute abdominal disease. In: Equine acute abdomen. Philadelphia : Lea \& Febiger, 1990. p.310-335.

WILSON, D.A.; BAKER, G.J.; BOERO, M.J. Complications of celiotomy incisions in horses. Vet Surg, v.24, n.6, p.506514, 1995. 